\title{
Vacuum Delivery in a Tertiary Institution, in Northern Nigeria: A 5-Year Review
}

\author{
I. A. Yakasai*, I. S. Abubakar, E. M. Yunus \\ Department of Obstetrics and Gynaecology, Bayero University Kano/Aminu Kano Teaching Hospital, Kano, \\ Nigeria \\ Email: ibrahimyakasai57@hotmail.com
}

Received 11 January 2015; accepted 10 April 2015; published 13 April 2015

Copyright (C) 2015 by authors and Scientific Research Publishing Inc.

This work is licensed under the Creative Commons Attribution International License (CC BY).

http://creativecommons.org/licenses/by/4.0/

(c) (i) Open Access

\section{Abstract}

Background: There is a progressive shift away from the use of forceps in favour of the vacuum extractor as the instrument of choice for operative vaginal deliveries. The overall objective of this is to improve safe motherhood by reducing the contribution of second stage of labour complications to maternal mortality and morbidity. Objective: This study was carried out to determine the incidence, indications, outcome and complications of Ventouse delivery in Aminu Kano Teaching Hospital, Kano, Nigeria. Materials and Methods: This was a retrospective study carried out at the Aminu Kano Teaching Hospital. The case notes of all parturients who had vacuum deliveries in the hospital within January 2008 to December 2012 were retrieved from the statistics unit of the hospital and analysed using SPSS. Results: 22,680 patients delivered in the hospital over this 5-year period. Ventouse was used on 210 occasions giving an incidence rate of $0.9 \%$. One hundred and eighty $(85.7 \%)$ had successful vacuum delivery. The failed extractions $(14.3 \%)$ were delivered by caesarean sections. The mean age of the patients was 29.4 years. The mean parity was 2.2 . Ninety (42.9\%) were primipara while $120(57.1 \%)$ were multipara. The commonest indication for the vacuum delivery was prolonged second stage of labour in $45.2 \%$ of cases. The commonest maternal complication was primary postpartum haemorrhage $(9.5 \%)$. Foetal complication occurred in about $31 \%$ of vacuum deliveries, the commonest (18.1\%), being cephalhaematoma. Conclusion: The incidence rate of vacuum delivery is low. Thus, active training in the art of vacuum assisted vaginal delivery is clearly needed during residency.

\section{Keywords}

Vacuum, Maternal Complications, Fetal Outcome

\footnotetext{
${ }^{*}$ Corresponding author.
}

How to cite this paper: Yakasai, I.A., Abubakar, I.S. and Yunus, E.M. (2015) Vacuum Delivery in a Tertiary Institution, in Northern Nigeria: A 5-Year Review. Open Journal of Obstetrics and Gynecology, 5, 213-218. 


\section{Introduction}

The past 20 years have seen a progressive shift away from the use of forceps in favour of the vacuum extractor as the instrument of choice [1] [2]. Although the overall rate of operative vaginal delivery has been declining, the proportion of vacuum-assisted deliveries has been increasing and now accounts for almost four times the rate of forceps-assisted vaginal births [3]. Vacuum extraction which is a common technique of assisted vaginal delivery was preferred to forceps assisted vaginal delivery because the skill is easily acquired compared to the forceps and is considered safer [4] [5]. Thus in developing countries where specialists are lacking in most facilities, it is easier to train the non-specialists doctors to use the vacuum extractor. In addition, vacuum has in-built safety mechanism; pop-off when excessive force is applied. This makes it a safe instrument even in the hands of inexperience. The ventouse can be used in the late first stage of labour at $8 \mathrm{~cm}$ cervical dilatation and above for foetal distress or cord prolapsed [4]. This is a very significant advantage over the forceps in African setting. By sparing these women with caesarean section, they are encouraged to return to the hospital in subsequent pregnancies [6] [7].

The incidence of operative vaginal delivery in the United States is currently estimated at around 5\%, and approximately $66 \%$ of operative vaginal deliveries were by vacuum [1]. Operative vaginal delivery rates have remained stable at between $10 \%$ and $13 \%$ in the UK, yielding safe and satisfactory outcomes for the majority of mothers and babies. However in Nigeria, vacuum delivery rates of $0.6 \%, 1.5 \%, 1.67 \%$ and $2.9 \%$ were reported in Jos, Enugu, Maiduguri and Lagos respectively [7]-[10] and they were much lower than the developed Nations.

Operative vaginal delivery is used to shorten the second stage of labour. It may be indicated for non-reassuring foetal status to prevent hypoxic brain damage or foetal death [11] [12]. Maternal conditions where down bearing effort is not encouraged, such as cardiac failure and hypertensive disease in pregnancy are also indications for instrumental delivery [11]. However, the decision to perform forceps or vacuum is not always straight forward. Forceps is more preferable where maternal expulsive effort is discouraged. Vacuum extraction requires maternal effort. But even in such situations like hypertensive disorders of pregnancy, vacuum extraction can yield similar result to forceps as it shortens second stage of labour with minimal maternal efforts [13].

The following conditions must be fulfilled before application of a vacuum extractor to avoid or minimise maternal and foetal complications: the presentation must be vertex, foetal membrane must be ruptured, gestational age must not be $<34$ weeks, head must be engaged to rule out cephalopelvic disproportion except in case of second twin with vertex presentation, there must be $8 \mathrm{~cm}$ or more cervical dilatation, the bladder must be emptied, the skills must be there and patient consent must be obtained [10] [13].

The goal of vacuum extraction is correct placement of the vacuum cup on the fetal scalp and creation of a vacuum of up to $0.8 \mathrm{~kg} / \mathrm{cm}^{2}$ to suck part of the scalp into the cup and create an artificial caput succedaneum (chignon) and then pull to deliver the baby [13] [14]. If delivery is not successfully executed after two to three pulls in a well selected patient the procedure should be abandoned [14] [15].

Episiotomy refers to a surgical incision in the perineum designed to enlarge the vagina and assist in childbirth [1]. Although episiotomy has often accompanied operative vaginal delivery, recent evidence suggests that routine use of episiotomy with vacuum extraction is associated with an increased rather than decreased risk of perineal trauma and rectal injuries [1]. Episiotomy during operative vaginal delivery also increases the incidence of postpartum haemorrhage, perineal infection, the need for stronger analgesia [1]. Taken together, these data suggest that routine episiotomy during vacuum extraction should be discouraged. Episiotomy, however, should be given if there is imminent perineal tear [9] [13].

Perineal laceration is the commonest maternal injury associated with ventouse delivery [16]. Other complications include annular detachment of the cervix if it was entrapped during vacuum application, cervical incompetence and uterine prolapse if traction occurs before full cervical dilatation [17] [18].

Nearly all neonates delivered with the assistance of a vacuum will exhibit visible scalp effects to a varying degree at the site of cup attachment. However, the majority are transient and of no clinical significance to the baby, but may cause considerable anxiety to the unprepared parent [13] [18]. The more significant injuries are, more often than not, related to misplacement of the cup, excessive or poorly directed traction, or cephalopelvic disproportion. More difficult vacuum deliveries, such as in occiput posterior and transverse positioned foetus as well as foetus at midstation, predispose to increased scalp injuries. However, the majority can be avoided with good patient selection, correct cup placement, avoidance of prolonged or misguided traction, and avoidance of cup detachments ("pop-offs”) [18]. 
Retinal haemorrhages occur more commonly in neonates delivered by vacuum, compared to normal spontaneous deliveries or forceps-assisted deliveries [5] [17] [18]. However, the haemorrhage is transient with no apparent long-term developmental or any ophthalmological consequences [18]. Cephalohematomas resolve within several days, but large ones may take up to several weeks, with no specific therapy required [18] [19]. A subgaleal haemorrhage is formed by ruptured emissary veins that bleed into the potential space between the scalp aponeurosis, or galea aponeurotica, and the periosteum of the cranial bones. Unlike the cephalohematoma, suture lines do not limit this potential space, thus infants can lose up to $80 \%$ of their blood volume into this potential space [18]. Affected neonate may present with symptoms of hypovolemic shock, in addition to the diffuse and dependent swelling of the cranium [18] [19]. Therefore, it is important that every neonate who undergoes a vacuum assisted delivery receives directed attention to the scalp at periodic intervals to detect evidence of diffuse swelling.

This study was carried out to determine the incidence of vacuum assisted vaginal deliveries, indications and associated maternal and fetal morbidity at the Aminu Kano Teaching Hospital, Kano, Nigeria.

\section{Materials and Methods}

This was a retrospective descriptive study carried out at the Aminu Kano Teaching Hospital, Kano Nigeria. The case records of all the patients who had vacuum assisted vaginal deliveries managed between January, 2008 and December, 2012 were retrieved. The outcome measures were the socio-demographic characteristics of the patients, indication for the vacuum delivery, complications and failed vacuum that resulted in caesarean section. The data obtained were analyzed using SPSS, and presented in tabular form using frequencies and percentages, mean and standard deviation. The number of deliveries during the study period was obtained from the statistics unit of the hospital.

\section{Results}

22,680 patients delivered at the hospital over this 5 year period. The ventouse was used on 210 occasions giving a prevalence rate of $0.9 \%$. Among the cases $41.2 \%$ were conducted by registrars, $47.4 \%$ by senior registrars and $11.4 \%$ by Consultants. One hundred and eighty (85.7\%) had successful vacuum delivery. The failed extractions (14.3\%) were delivered by caesarean section. The mean age of the patients was $23.5 \pm 7$ years. The mean parity was 2.2. Among the 210 mothers, 90 were primiparas, 55 were multiparas and 65 were grand multiparas. The commonest indication for the vacuum delivery was prolonged second stage of labour in $45.2 \%$ of cases. Shortening of the second stage of labour for maternal disease conditions was done in $36.7 \%$, and foetal distress accounted for $18.1 \%$. The commonest maternal complication was primary postpartum haemorrhage (9.5\%). Foetal complication occurred in about $31 \%$ of ventouse deliveries, with the commonest (18.1\%), being cephalhaematoma. Foetal asphyxia occurred in 10 (4.8\%) while 8 (3.8\%) had stillbirth (Tables $1-3)$.

\section{Discussion}

The incidence rate of vacuum deliveries in this review was $0.9 \%$. This is higher than $0.6 \%$ in Jos, but significantly lower than vacuum delivery rates of $1.5 \%, 1.67 \%$ and $2.9 \%$ reported from Enugu, Maiduguri, Lagos and

Table 1. Age distribution of vacuum deliveries.

\begin{tabular}{ccc}
\hline AGE RANGE & FREQENCY & PERCENTAGE \\
\hline $15-19$ & 60 & 28.6 \\
$20-24$ & 30 & 14.3 \\
$25-29$ & 26 & 12.4 \\
$30-34$ & 29 & 13.8 \\
$35-39$ & 21 & 10.0 \\
$40-44$ & 28 & 13.3 \\
$45-49$ & 16 & 7.6 \\
TOTAL & 210 & 100 \\
\hline
\end{tabular}


Table 2. Indications for vacuum deliveries.

\begin{tabular}{ccc}
\hline INDICATIONS & FREQUENCY & PERCENTAGE \\
\hline Prolonged second stage & 95 & 45.2 \\
Fetal distress & 38 & 18.1 \\
Preeclampsia & 50 & 23.8 \\
Maternal cardiac disease & 8 & 3.8 \\
Sickle cell disease in pregnancy & 19 & 9.1 \\
TOTAL & 210 & 100 \\
\hline
\end{tabular}

Table 3. Maternal and fetal complications.

\begin{tabular}{ccc}
\hline COMPLICATIONS & FREQUENCY & PERCENTAGE \\
\hline Cervical laceration & 6 & 2.9 \\
Extension of episiotomy & 12 & 5.7 \\
Primary postpartum haemorhage & 19 & 9.5 \\
Cephalhaematoma & 38 & 18.1 \\
Scalp bruising & 9 & 4.3 \\
Birth asphyxia & 10 & 4.8 \\
Stillbirth & 8 & 3.8 \\
\hline
\end{tabular}

Ghana respectively [7]-[10] [20]. The incidence of vacuum assisted vaginal delivery in the United States is currently estimated at around 3.3\% [1] [21]. An explanation of the low rate of operative vaginal delivery in general is due to the fact that majority of the procedures were performed by residents who may have reduced confidence zone with vacuum delivery and low threshold for caesarean section [7] as cesarean delivery is increasingly accessible and acceptable, reaching levels as high as $30 \%$ in the public sector and $70 \%$ in the private sector in Brazil [22]. Most of the vacuum deliveries in this study $88.3 \%$ were carried out by resident doctors (senior registrars $47.4 \%$, registrars $41.2 \%$ ) and only $11.4 \%$ by consultants, which may explain the high failed vacuum rate in this study, and call for more consultants input in the conduct of vacuum delivery. In this study, 30 (14.3\%) who had failed vacuum were delivered by caesarean section because sequential use of forceps to complete the delivery have been associated with increased risk of injuries to the fetus and maternal genital tract unless the failure occurred with the fetal head visible at the outlet of the pelvis [23] (Figure 1).

With a mean age of $23.5 \pm 7$ years, this study revealed that most of the parturients who had vacuum deliveries were young adults. This study also revealed that vacuum deliveries were more frequently performed in primigravida, who constituted $42.9 \%$ of parturients in this study. Similar observations were made in Jos Canada and the United Kingdom which may not be unconnected with the higher tendency to second stage delays in primigravida [8] [24] [25], which was the most common indication for operative vaginal delivery in this study. Tight, untested lower genital tracts, undue anxiety, and inexperience in labour among young aged primigravida no doubt accounted for the higher frequency of this diagnosis.

Operative vaginal delivery is used to shorten the second stage of labour. It may be indicated for prolonged second stage of labour, maternal exhaustion or foetal conditions including non-reassuring foetal status to prevent hypoxic brain damage or foetal death [12] [13] [24]. Prolonged second stage of labour was the most common indication in our study and accounted for $45.2 \%$ which was similar to other studies in Jos and Maiduguri [8] [9]. Shortening of the second stage of labour for maternal disease conditions where bearing down effort is not encouraged was done in $36.7 \%$. This was comparable to $38.0 \%$ in Jos [8]. The commonest maternal complication was primary postpartum haemorrhage (9.5\%). This was similar to the finding in Enugu [7]. Prolonged labour, and genital tract laceration may explain this [25]. Thus, there is need to anticipate postpartum haemorrhage in operative vaginal deliveries and therefore third stage of labour should be managed actively and genital tract lacerations repaired immediately to minimise blood loss. 


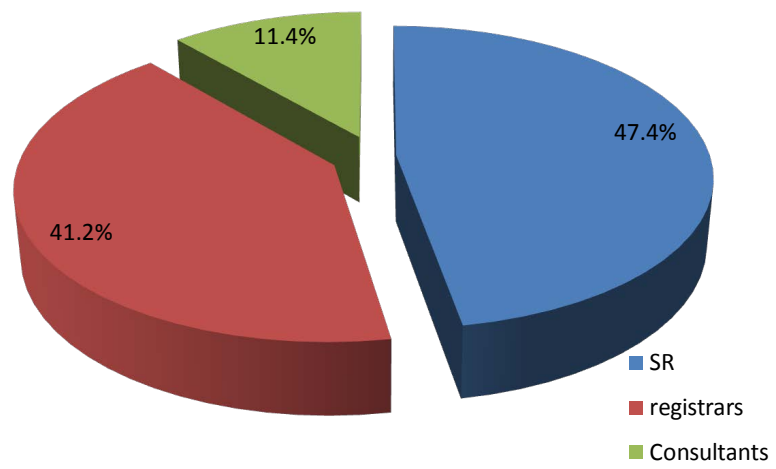

Figure 1. Level of obstetrician performing vacuum delivery.

Vacuum deliveries can cause significant fetal morbidity [1]. This occurred in about $31 \%$ of ventouse deliveries in this study, with the commonest (18.1\%), being cephalhaematoma. Significantly higher rates of cephalhematomas have been reported in other studies after vacuum application [26]-[28]. The rates of sever birth asphyxia and stillbirth were $4.8 \%$ and $3.8 \%$ respectively. This compares to the findings of various studies and may not be truly attributable to the procedure as the asphyxia may be the outcome of the events of labour that indicated the intervention than from the operative vaginal procedure itself [1] [8] [29]. Paediatricians should be notified whenever an operative vaginal delivery has been attempted and whether it was successful because serious morbidity can present several hours after birth [1] [26] [30].

\section{Conclusion}

The commonest indication for vacuum delivery was prolonged second stage and the complication was minimal. The incidence of vacuum delivery is currently low. In order to reverse the trend and for this skill to continue, active training in the art of vacuum delivery is clearly needed during residency training. With appropriate training and careful patient selection, vacuum is a valuable and safe tool in the hands of the practicing obstetricians.

\section{References}

[1] Unzila, A.A. and Errol, R.N. (2009) Vacuum-Assisted Vaginal Delivery. Reviews in Obstetrics \& Gynecology, 2, 5-17.

[2] Baskett, T.F., Fanning, C.A. and Young, D.C. (2008) A Prospective Observational Study of 1000 Vacuum Assisted Deliveries with OmniCup Device. Journal of Obstetrics \& Gynaecology, 30, 573-580.

[3] Clark, S.L., Belfort, M.A. and Hankins, G.D. (2007) Variation in the Rates of Operative Delivery in the United States. American Journal of Obstetrics and Gynecology, 196, 526.e1-526.e5. http://dx.doi.org/10.1016/j.ajog.2007.01.024

[4] Odoi, A.T. and Opare-Addo, H.S. (2002) Operative Vaginal Delivery, Forceps Delivery and Vacuum Extraction. In: Kwawukume Emuveyan, E.E., Ed., Comprehensive Obstetrics in the Tropics, Asante and Hittscher Printing Press Limited, Accra, 340-351.

[5] O’Mahony, F., Hofmeyr, G.J. and Menon, V. (2010) Choice of Instruments for Assisted Vaginal Delivery. Cochrane Database of Systematic Reviews, No. 11, Art. No.: CD005455. http://dx.doi.org/10.1002/14651858.CD005455.pub2

[6] Johnson, R.B. and Menon, V. (1999) Vacuum Extraction versus Forceps for Assisted Vaginal Delivery. Cochrane Database of Systemic Review, No. 2, Art. No.: CD000224.

[7] Chukwuemeka, A.I. and Hyacinth, E.O. (2006) Vacuum Deliveries at the University of Nigeria Teaching Hospital Enugu. Tropical Journal of Obstetrics and Gynaecology, 23, 23-26.

[8] Mutihir, J.T. and Pam, V.C. (2007) Vacuum Delivery in Jos University Teaching Hospital, Jos Nigeria. Journal of Medicine in the Tropics, 19, 21-28.

[9] Abdulkarim, G.M., Othman, K. and Bala, M.A. (2005) Instrumental Vaginal Deliveries at the University of Maiduguri Teaching. Tropical journal of Obststerics and Gynaecology, 22, 42-45.

[10] Ogedengbe, O.K. and Odeneye, T.O. (2004) Outcome of Instrumental Deliveries in Lagos Nigeria; Implications for Its Use at the Second Tier Healthcare Level. Nigerian Medical Practitioner, 45, 106-110. http://dx.doi.org/10.4314/nmp.v45i6.28714

[11] Attilakos, G., Sibanda, T., Winter, C., Johnson, N. and Draycott, T. (2005) A Randomised Controlled Trial of a New Handheld Vacuum Extraction Device. BJOG: An International Journal of Obstetrics \& Gynaecology, 112, $1510-1515$. 
http://dx.doi.org/10.1111/j.1471-0528.2005.00729.x

[12] Edozien, L.C. (2007) Towards Safe Practice in Instrumental Vaginal Delivery. Best Practice \& Research Clinical Obstetrics \& Gynaecology, 21, 639-655. http://dx.doi.org/10.1016/j.bpobgyn.2007.03.006

[13] Cunningham, F.G., Gant, N.F., Leveno, K.J., Gilstrap, L.C., Hauth, J.C., et al. (2001) Forceps Delivery and Vacuum Extraction. 21st Edition, MacGraw-Hill, USA: Williams Obstetrics, 485-508.

[14] Dutta, D.C. (1998) Normal Labor. In: Hiralal, K, Ed., Textbook of Obstetrics Including Perinatology and Contraception, 4th Edition, New Central Book Agency Ltd., India, 118-152.

[15] Beischer, N.A. and Mackay, E.U. (1986) Dystocia. In: Obstetrics and the Newborn, 2nd Edition, Balliere Tindall, London, 443-462.

[16] Yakasai, A.I., Abubakar, I.S. and Abdullahi, H. (2011) An Audit of Instrumental Vaginal Delivery in Aminu Kano Teaching Hospital, Kano. Tropical Journal of Obstetrics and Gynaecology, 28.

[17] Kwame-Aryee, R.A. (1999) 2nd Stage of Labor. In: Handbook of Obstetrics, 1st Edition, Max Associates Limited, Ghana, 30-34.

[18] Johnson, R.B. and Menon, V. (2000) Soft versus Rigid Vacuum Extractor Cups for Assisted Vaginal Delivery. Cochrane Database System Review, No. 2, Art. No.: CD000446. http://dx.doi.org/10.1002/14651858.CD000446

[19] McQuivey, R.W. (2004) Vacuum-Assisted Delivery: A Review. The Journal of Maternal-Fetal \& Neonatal Medicine, 16, 171-180. http://dx.doi.org/10.1080/jmf.16.3.171.180-25

[20] Gumanga, S.K., Kwame-Aryee, R., Seffah, J.D. and Amuzu, S.K. (2012) Ten-Year Review of Vacuum Assisted Vaginal Deliveries at a District Hospital in Ghana. West African Journal of Medicine, 31, 192-197.

[21] Prapas, N., Kalogiannidis, I., Masoura, S., Diamanti, E., Makedos, A., Drossou, D. and Makedos, G. (2009) Operative Vaginal Delivery in Singleton Term Pregnancies: Short-Term Maternal and Neonatal Outcomes. Hippokratia, 13, 4145.

[22] Bailey, P.E. (2005) The Disappearing Art of Instrumental Delivery: Time to Reverse the Trend. International Journal of Gynecology \& Obstetrics, 91, 89-96. http://dx.doi.org/10.1016/j.ijgo.2005.05.016

[23] Vacca, A. (2006) Reducing the Risk of a Vacuum Delivery. Fetal and Maternal Medicine Review, 17, 301-315. http://dx.doi.org/10.1017/S0965539506001823

[24] RCOG Green Top a Guidelines No. 29 January 2011 Operative Vaginal Deliveries.

[25] Baskett, T.F., Fanning, C.A. and Young, D.C. (2008) A Prospective Observational Study of 1000 Vacuum Assisted Vaginal Deliveries with OmniCup Device. Journal of Obstetrics and Gynaecology Canada, 30, 573-580.

[26] Ijaiya, M.A., Aboyeji, A.P. and Abubakar, D. (2003) Analysis of 348 Consecutive Cases of Primary Postpartum Haemorhage at a Tertiary Hospital in Nigeria. Journal of Obstetrics \& Gynaecology, 23, 374-377. http://dx.doi.org/10.1080/0144361031000119529

[27] Caughey, A.B., Sandberg, P.L., Zlatnik, M.G., Thiet, M.P., Parer, J.T. and Laros, R.K. (2005) Forceps Compared with Vacuum: Rates of Neonatal Maternal Morbidity. Obstetrics \& Gynecology, 106, 908-912. http://dx.doi.org/10.1097/01.AOG.0000182616.39503.b2

[28] Bofill, J.A., Rust, O.A., Schorr, S.J., Brown, R.C., Martin, R.W., Martin Jr., J.N. and Morrison, J.C. (1996) A Randomised Prospective Trial of Obstetric Forceps versus the M-Cup Vacuum Extractor. American Journal of Obstetrics and Gynecology, 175, 1325-1330. http://dx.doi.org/10.1016/S0002-9378(96)70049-2

[29] Johnson, J.H., Figueroa, R., Garry, D., Elimian, A. and Maulik, D. (2004) Immediate Maternal and Neonatal Effects of Forceps and Vacuum-Assisted Deliveries. Obstetrics \& Gynecology, 103, 513-518. http://dx.doi.org/10.1097/01.AOG.0000114985.22844.6d

[30] Adaji, S.E., Shittu, S.O. and Sule, S.T. (2009) Operative Vaginal Deliveries in Zaria, Nigeria. Annals of African Medicine, 8, 95-99. http://dx.doi.org/10.4103/1596-3519.56236 